\title{
UNCOVERING LEARNERS' EXPERIENCES TO NEW NORMAL EDUCATION: IMPLICATIONS OF ASYNCHRONOUS INSTRUCTION IN GE 5: SCIENCE, TECHNOLOGY, AND SOCIETY COURSE TEACHING
}

\author{
Jeneva J. Diez, \\ Emiernafe M. Ebro, \\ Ronna Joy C. Dequito, \\ Tomas Jr A. Diquito ${ }^{i}$ \\ University of Mindanao Digos College, \\ Digos City, Davao del Sur, \\ Philippines
}

\begin{abstract}
:
The new normal education policy in response to the pandemic crisis pushed institutions to shift from traditional face-to-face to asynchronous instruction that posed challenges particularly to science courses in higher education. The purpose of this study was to understand the learning experiences of the students and the implications of asynchronous teaching instruction in the Science, Technology, and Society course. This study utilized a convergent parallel mixed method of research employing descriptivecomparative and descriptive phenomenological research designs. There were 100 respondents for the quantitative part and 12 participants for the qualitative part. Based on the quantitative findings, the overall implementation of asynchronous instruction in the course was "excellent." Specifically, the level of implementation was "very satisfactory" in terms of Content and Course Evaluation, while "excellent" in terms of Instructional Design, Student Assessment, and Technology. There was no significant difference in the level of implementation of the course asynchronous instruction when analyzed by specialization. Moreover, based on the qualitative analysis, the learning experiences of students in asynchronous instruction were both positive and negative that implied two-way learning experiences. The general recommendation gleaned from the students was science, technology, and society asynchronous delivery improvement that covered teacher improvement, SIM improvement, and assessment tool improvement. The general recommendations of this study were improving asynchronous instruction delivery through teachers training proposals, modification of self-instructional materials, increasing the awareness and effective use of the varied assessment tools in sustaining the needs and interest of students in studying the course, creating a safe learning

${ }^{i}$ Correspondence: email miraij460@gmail.com, eemiernafie@gmail.com, ronnajoydequito072@gmail.com, tomasdiquito23@gmail.com
\end{abstract}


environment for the students, and conducting future researches to reveal significant factors which affect the learning experiences of students and the other points that the current researchers have not yet explored.

Keywords: learning experience, asynchronous instruction, education in new normal, science, technology, and society

\section{Introduction}

One of the challenges in teaching is to seek effective instruction to use. Due to COVID 19 pandemic, schools worldwide, both Basic and Higher education, adjusted to the new normal situation wherein one of the modalities is asynchronous instruction. Asynchronous instruction is situated based on the schedule of students to provide a wellmanaged learning environment. Although it is widely used for distanced learning, the challenges it imposes on the teacher-student interaction and the course need to be investigated for the teaching-learning process to succeed. Moreover, the outbreak of virus and lockdown has imposed a critical problem in education. According to the United Nations Educational, Scientific, and Cultural Organization (2020), more than 1.57 billion students in over 190 countries have been affected by school closures due to COVID19. The economic impact it entails on low-income countries like Sub-Saharan Africa permits a smooth shift of learning instruction from traditional teaching to distanced education (Azzi-Huck \& Shmis, 2020). As a result, the digital divide comes into place, which hinders new normal learning foster.

In the Philippine context, educational sectors are overwhelmed with the integration of the new learning system. In the recent survey by UNESCO (2020), over 28 million Filipino learners across academic levels have to stay at home and comply with the Philippine quarantine measures. With this action, a common problem that burdens the Filipino learner is poor access to an internet connection. According to the Department of Information and Communications Technology (2019), only 17.7\% of Filipino households have internet access; $24 \%$ own phones and, $23.8 \%$ own computers connected to the internet. For learning to continue in higher education, the Commission on Higher Education (CHED) opted for flexible learning as an alternative to overcome the barrier set by the new normal education (Villanueva, 2020). Moreover, the Open Distance Learning Act (RA 10650) promoted Universities and Colleges, including The University of Mindanao to utilize synchronous and asynchronous instruction as an efficient learning modality when physical classrooms are not yet available (CHED, 2016). However, a survey from the University of Mindanao-Institute of Popular Opinion (UM-IPO) revealed that three out of 10 college students are generally hesitant to the new normal learning setup across Higher Education Institutions (HEI) in Davao City (Llemit, 2020). 
The shift of teaching strategies in the new normal education has affected most students learning in higher education. Teaching in Science courses like in Science, Technology, and Society has been a constant challenge, especially in sustaining the learning engagement. This gap has motivated us to understand the learning experiences of students in the new normal education. Since learners are the most vulnerable in this novel setup, the implications from students' experiences generate significant recommendations in the asynchronous delivery of instruction. This includes the evaluation of self-instructional materials and the effort to uplift teaching standards through activity proposals towards the success of student learning.

\section{Objectives of the Study}

This study aimed to understand the learning experiences of the students and the implications of asynchronous teaching instruction in GE 5: Science, Technology, and Society course at UMDC.

Specifically, this study sought to explore the following queries:

1) Determine the level of implementation of GE 5: Science, Technology, and Society asynchronous instruction.

2) Determine if there is a significant difference in the level of implementation of asynchronous instruction in GE5: Science, Technology, and Society among students.

3) Describe the learning experiences of GE 5: Science, Technology, and Society college students

\section{Method}

To carry out the objectives of the study, the following have been applied:

\subsection{Research Design}

This study utilized a parallel method of research. The quantitative part of the study employed a descriptive-comparative design to evaluate the asynchronous instruction in GE 5 course teaching and purposefully select participants for the second part. The qualitative part of the study utilized a descriptive phenomenology design to describe the lived experiences of individuals like learning in an asynchronous instruction (Creswell, 2009).

\subsection{Respondents}

The study utilized randomly selected education students who have taken GE 5 course in the academic year 2020-2021. The quantitative part adopted simple random sampling (Creswell, 2009). The criteria for selecting the participants will include: have taken GE 5 course, enrolled either in the first and second semester of the academic year 2020-2021, 
being an education student and bonafide student of the University of Mindanao Digos College. The qualitative part of this study utilized a purposeful sample. We selected the participants who can help us best to understand the research problem and the research questions (Creswell, 2009). A total of 12 students (Creswell \& Miller, 2002) from six specializations with the most enrollee in the Department of Teacher Education in UMDC participated in the interview.

\subsection{Research Instruments}

In the quantitative part of the study, we used a survey questionnaire to evaluate the implementation of GE 5 asynchronous instruction adapted from the Checklist for Evaluating Online Courses Educational Technology Cooperative by the Southern Regional Education Board (2006). Experts examined the instrument to ensure its reliability and validity. A pilot test took place before administering the instrument to a larger sample size of the study. In the qualitative part of the study, researchers constructed an interview questionnaire based on quantitative findings. The interview questions focused on the learning experience of the students in GE 5 asynchronous instruction. Additionally, it included a set of questions to improve the implementation. The researcher-made interview questionnaire underwent validation.

\subsection{Data Analysis}

Mean and Analysis of Variance facilitated the quantitative data analysis and thematic analysis for the qualitative data.

\section{Results and Discussion}

\subsection{Level of implementation of asynchronous instruction in GE5 course}

The following table shows the level of implementation of asynchronous instruction in the GE5 course. The level of implementation of asynchronous instruction in the GE5 course considered five components: Content, Instructional Design, Student Assessment, Technology, and Course Evaluation. The results revealed that the level of implementation of asynchronous instruction in the GE5 course obtained an overall mean of $4.21(\mathrm{SD}=0.63940)$ with a descriptive meaning of "excellent."

Table 2: Level of implementation of asynchronous instruction in GE5 course teaching $(\mathrm{n}=100)$

\begin{tabular}{lcc}
\hline Components & Mean & Standard Deviation \\
\hline Content & 4.20 & .66264 \\
Instructional Design & 4.22 & .70495 \\
Student Assessment & 4.23 & .65923 \\
Technology & 4.21 & .65637 \\
Course Evaluation & 4.19 & .70314 \\
Overall & 4.21 & .63940 \\
\hline
\end{tabular}


The Content evaluation for the implementation of asynchronous instruction in the GE5 course obtained a Mean of $4.20(\mathrm{SD}=0.66264)$ with the descriptive meaning "very satisfactory." Content included the evaluation of academic content standards and assessments course, overview and introduction, legal and acceptable use policies, teacher resources. Measures of course/instructional design, teaching materials, well-organized content, assessment methodologies, explicit course aim and expectations, alignment of instructional content and assessment, perceived ease of use, and workload were all used to determine course quality ( $\mathrm{Li}$, Marsh \& Rientes, 2016). In online learning, course design and quality have a significant impact on student satisfaction: students are more satisfied with well-designed online courses that have clear goals and are simple to navigate (Ghaderizefreh \& Hoover, 2018).

The Instructional Design evaluation for the implementation of asynchronous instruction in the GE5 course obtained a Mean of $4.22(\mathrm{SD}=0.70495)$ with the descriptive meaning "excellent." Instructional Design included an evaluation according to instructional and audience analysis; course, unit, and lesson design; goals/objectives; instructional strategies and activities; and communication and interaction resources and materials. Ghaderizefreh and Hoover (2018) argue that distance learning course materials that are designed and produced using empirical research cater to the learners and achieve their intended learning outcomes. To decide what types of information and activities will support learning outcomes, instructional designers must consider the learner's past knowledge and experience. A frequent assumption is that lowering the cognitive load is always advantageous. However, it is the source of the load that is important, not the amount of load. So that germane cognitive load is as high as feasible, tasks should be entertaining and challenging. However, what is beneficial to an advanced learner may be overwhelming to a newbie. Knowing about the student allows educators to create projects and ask questions at the appropriate level to help them learn more effectively (Darling-Hammond, Flook, Cook-Harvey, Baron \& Osher, 2019).

Meanwhile, Student Assessment evaluation for the implementation of asynchronous instruction in the GE5 course obtained a Mean of $4.23(\mathrm{SD}=0.65923)$ with the descriptive meaning "excellent." Evaluation of Student Assessment is based on evaluation strategies, adequate and appropriate methods and procedures, feedback, and assessment resources and materials. Assessment allows instructors to define the metrics of evaluation for student knowledge and achievement in course goals (Wiggins \& McTighe, 2005; in Fisher \& Bandy, 2019). It was also noted that critical reflection on one's teaching is an important element of growing as an educator and improving students' learning experiences. This reflection helps educators to see where their teaching has been successful in fulfilling learning objectives and where it has not, allowing for changes. Student assessments justify pedagogical decisions and allow teachers to analyze their teaching success (Brookfield, 1995; in Fisher \& Bandy, 2019).

Moreover, Technology evaluation for the implementation of asynchronous instruction in the GE5 course obtained a Mean of $4.21(\mathrm{SD}=0.65637)$ with the descriptive 
meaning "excellent." Technology utilized in e-learning was evaluated according to course architecture, user interface, technology requirements and interoperability, accessibility, and technical support. Darling-Hammond et al. (2019) and $\mathrm{Wu}$ (2016) found that while many applications of technology have been proven to be unsuccessful, those that support students' interests have been found to help them succeed. Workbook-style tasks, phonics, grammar, and punctuation exercises, drill on math topics, and practice with multiplechoice test questions were among the ineffective uses of technology. Meanwhile, simulations, games, data analysis, and writing were examples of effective uses in interactive learning, where technology was utilized to engage with data, explore and create, express ideas, and construct learning presentations, as well as peer conversations and teacher-led activities.

Finally, the evaluation of Course Evaluation and Management obtained a Mean of $4.19(\mathrm{SD}=0.70314)$ with the descriptive meaning "very satisfactory." This evaluation included assessing course effectiveness, updating courses, accreditation, and data security. Learning and assessment are mutually dependent because both students and teachers tend to pay greater attention to learning objectives that are assessed (Kelley, Fowlin, Tawfik \& Anderson, 2019). Martin, Ritzhaupt, Kumar, and Budhrani (2019) found that award-winning online faculty use a variety of assessments, using traditional and authentic assessments and used rubrics to assess students. This faculty suggested employing a variety of assessments for assessment and evaluation, including traditional and genuine assessments, rubrics to assess students, course templates and quality assurance processes, surveys, learning analytics, and peer reviews.

\subsection{Test of Difference on the Level of Implementation of Asynchronous Instruction in GE5 course among Students}

Table 3 shows the summary of the analysis of variance (ANOVA) on the level of implementation of asynchronous instruction in the GE5 course among students. The oneway ANOVA showed that there is statistically no significant difference at $\mathrm{p}<0.05, \mathrm{~F}$ $(10,89)=0.678, p=0.742$. This would mean that a significant difference cannot be concluded.

Table 3: Summary of Analysis of Variance on the Level of Implementation of Asynchronous Instruction in GE5 course among Students

\begin{tabular}{|l|l|c|c|c|c|c|}
\hline \multicolumn{2}{|c|}{} & Sum of Squares & df & Mean Square & F & Sig. \\
\hline \multirow{4}{*}{ Content } & Between Groups & 3.117 & 10 & .312 & .687 & .733 \\
\cline { 2 - 7 } & Within Groups & 40.353 & 89 & .453 & & \\
\cline { 2 - 7 } & Total & 43.470 & 99 & & & \\
\hline \multirow{3}{*}{$\begin{array}{l}\text { Instructional } \\
\text { Design }\end{array}$} & Between Groups & 2.464 & 10 & .246 & .469 & .906 \\
\cline { 2 - 7 } & Within Groups & 46.735 & 89 & .525 & & \\
\cline { 2 - 7 } & Total & 49.199 & 99 & & & \\
\hline \multirow{3}{*}{$\begin{array}{l}\text { Student } \\
\text { Assessment }\end{array}$} & Between Groups & 2.800 & 10 & .280 & .620 & .793 \\
\cline { 2 - 7 } & Within Groups & 40.224 & 89 & .452 & & \\
\cline { 2 - 7 } & Total & 43.024 & 99 & & & \\
\hline
\end{tabular}


Jeneva J. Diez, Emiernafe M. Ebro, Ronna Joy C. Dequito, Tomas Jr A. Diquito

UNCOVERING LEARNERS' EXPERIENCES TO NEW NORMAL EDUCATION:

IMPLICATIONS OF ASYNCHRONOUS INSTRUCTION IN GE 5: SCIENCE, TECHNOLOGY, AND SOCIETY COURSE TEACHING

\begin{tabular}{|l|l|c|c|c|c|c|}
\hline \hline \multirow{5}{*}{ Technology } & Between Groups & 3.203 & 10 & .320 & .723 & .701 \\
\cline { 2 - 7 } & Within Groups & 39.449 & 89 & .443 & & \\
\cline { 2 - 7 } & Total & 42.652 & 99 & & & \\
\hline \multirow{3}{*}{$\begin{array}{l}\text { Course } \\
\text { Evaluation }\end{array}$} & Between Groups & 4.181 & 10 & .418 & .831 & .600 \\
\cline { 2 - 7 } & Within Groups & 44.765 & 89 & .503 & & \\
\cline { 2 - 7 } & Total & 48.946 & 99 & & & \\
\hline \multirow{3}{*}{ Overall } & Between Groups & 2.866 & 10 & .287 & .678 & .742 \\
\cline { 2 - 7 } & Within Groups & 37.608 & 89 & .423 & & \\
\cline { 2 - 7 } & Total & 40.474 & 99 & & & \\
\hline${ }^{*} \mathrm{p}<0.05$ & \multicolumn{7}{|l|}{} \\
\hline
\end{tabular}

\subsection{Learning Experiences of GE 5 Students}

Theme 1: Two-Way Asynchronous Learning Experiences

The theme, Two-way Asynchronous Learning Experiences, emerged due to the varied statements of students from their experiences in taking the GE 5 (Science, Technology, and Society) course in an asynchronous instruction. Table 5 presents the different learning experiences of students in studying GE 5 (Science, Technology, and Society) courses in asynchronous instruction. It is clearly shown that the two-way asynchronous learning experiences emerged from its two main underlying categories which are the positive and negative experiences. Thus, the learners' experiences in GE 5 (Science, Technology, and Society) are realized from the stated personal responses.

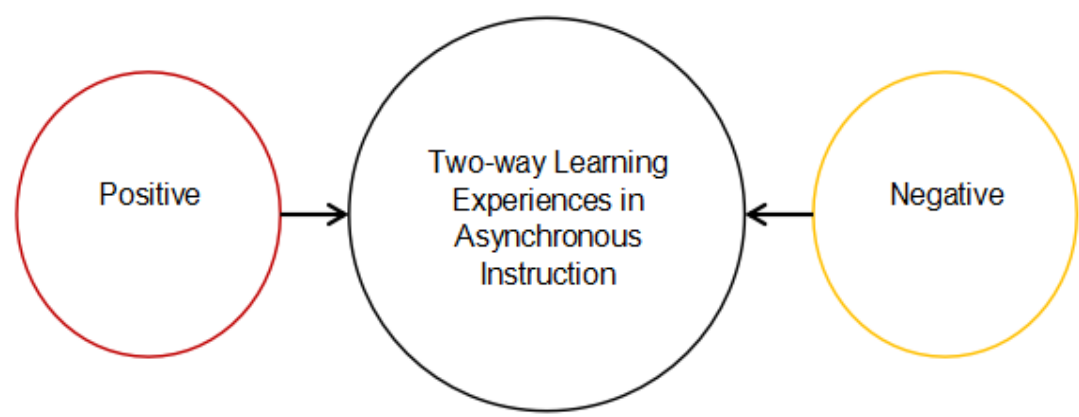

Figure 1: The Two-way learning experiences of GE 5 students in asynchronous instruction

\subsubsection{Two-way asynchronous learning experiences}

It mainly refers to the positive and negative experiences of students in studying this course. In student's positive experiences, important basic themes which are included are teachers' traits of being considerate and approachable, student's teamwork, and the module's comprehensiveness. Hussin, Harun, and Shukor (2019) emphasized that social learning can be used as an effective environment for online interaction wherein students and teachers can freely establish communication. As also stated by the theory of Vygotsky (1978), knowledge in social constructivism is viewed in a social context.

Moreover, the significance of interaction among students is proven to benefit the students towards a meaningful learning process. These involve student to student, teacher to student; and student to content interaction which provide a pedagogical 
foundation to an effective teaching-learning experience in an open distanced learning environment (Berg, 2020). On the contrary, negative experiences of students are also tackled. It consists of important basic themes like slow internet connection, difficulty in understanding concepts, LMS technical difficulties, and decrease of motivation among students. Mese and Sevilen (2021) claimed that the lack of motivation of students in distanced learning stems from dissatisfaction with course content and materials, lack of self-discipline; and lack of communication to teachers to adequately follow the course. Given that students need to be responsible for their learning, still, it is inevitable not to be conflicted with students' reasons for being unmotivated at times. Hence, realizing both positive and negative experiences among learners is important to provide a real understanding of student's stand in dealing with the course.

The different responses of the students have opened the positive side of learner's experiences in taking the GE 5 (Science, Technology, and Society) course in an asynchronous instruction. According to Mahler, Großschedl, and Harms (2018), successful teaching requires a positive teacher-student relationship that promotes enthusiasm and support in students' performance. Students may sometimes ask questions or further clarification, and the action of online instructors through showing interest and giving them appreciation have been essential in boosting student's motivation; and the way to great academic success. Coman, Meseșan-Schmitz, Stanciu, and Bularca, (2020) highlighted that teachers must be adaptive to students' needs since it is vital in increasing the engagement and involvement of students in the new learning situation. Additionally, students have pointed out that teachers being approachable has been helpful in their learning experiences. This enables a good relationship between student and teacher in today's learning environment, as students can freely talk about their concerns and experiences. Aside from that, it became a significant tool for students learning process. On the other hand, there are also learner's negative experiences while taking the GE 5 (Science, Technology, and Society) course. Common problems of having a slow internet connection, LMS technical problems, and lacking resources to support student learning are expressed by the students. Technical support is a crucial factor when it comes to realizing the effectiveness of the LMS. This agrees with the study of (Alshammari, 2020) which reveals that providing technical assistance to students can increase learning motivation.

\subsection{Recommendations from Student to Implement GE 5 Asynchronous Instruction Effectively}

Theme 2: GE 5 Asynchronous Delivery Improvement

The theme, GE 5 Asynchronous Delivery Improvement, emerged from the varied recommendations of students while taking the GE 5 (Science, Technology, and Society) course. It served as a significant consideration to implement the GE 5 course more effectively in asynchronous instruction. Figure 2 presents the different recommendations of students to implement the instruction effectively in the GE 5 (Science, Technology, and 
Society) course in an asynchronous instruction. The individual needs and circumstances of every student have influenced the recommendations being indicated in their responses. Moreover, the main theme, GE 5 asynchronous delivery improvement comes up from three significant categories, which are teacher's improvement, SIM improvements, and assessment tool improvement.

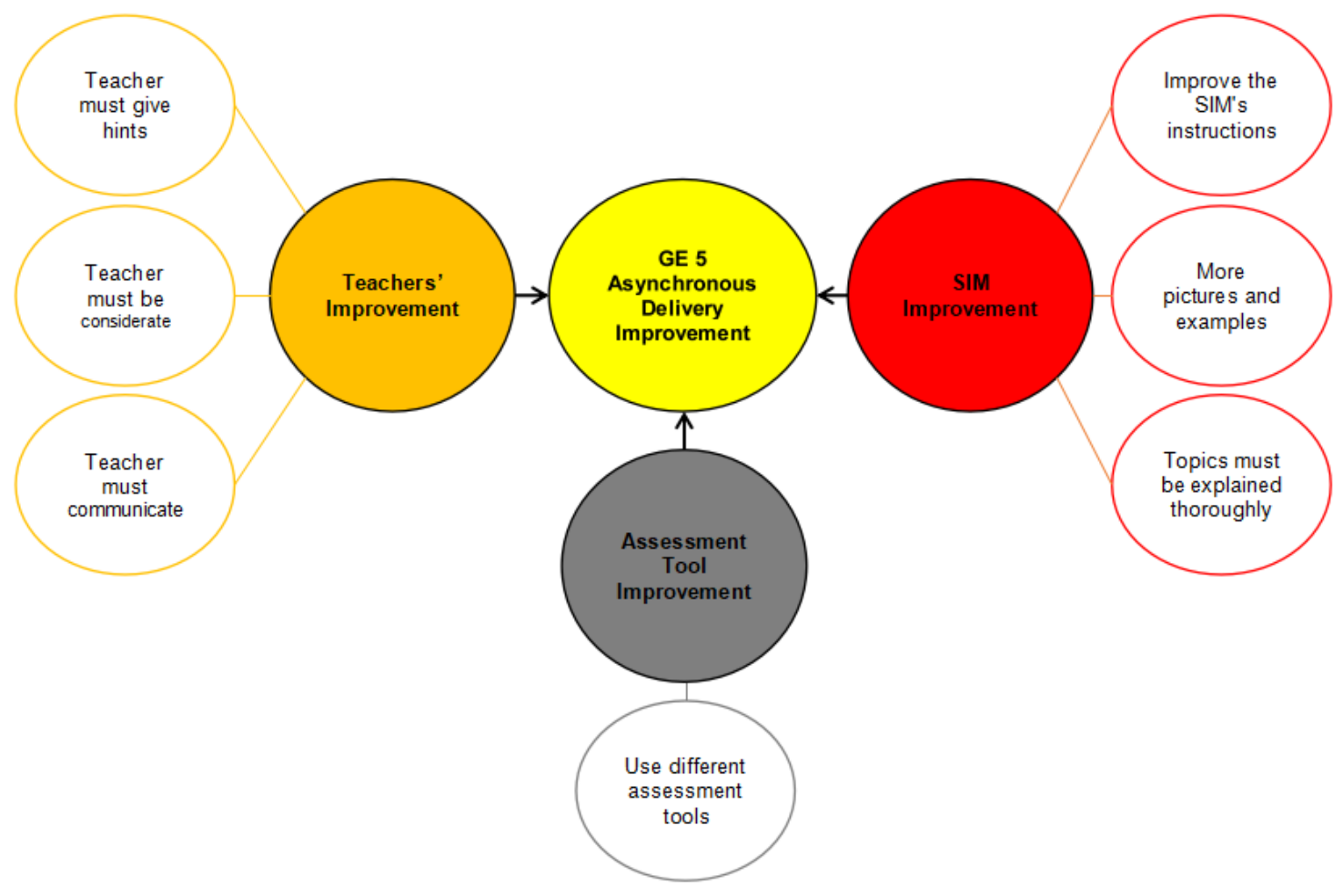

Figure 2: Recommendations of GE 5 students for effective course implementation

\subsubsection{GE 5 asynchronous delivery improvement}

This pertains to the needed improvements being determined from student's responses to enhance student's learning experience and towards the effective implementation of the GE 5 (Science, Technology and Society) course. First on the student's list is the teacher's improvements. Basic themes being included are the teacher's assistance to students through giving hints and the teacher's ability to consider and communicate to respective students. The significant role of teachers is realized most especially with institution's ventures with asynchronous instruction. Broadbent and Poon (2015) suggested that teachers' crucial role in maximizing the benefits of online environments like flexibility is relevant in the development of self-regulatory skills among students. This is supported by the idea of Vygotsky (1978) on social interaction and social support being vital to learning which significantly improves online learners' outcomes through scaffolding. Teachers are the known most significant other (MKO), which assists students in accomplishing a task while gradually increasing the learner's actual development level.

Moreover, self-instructional materials (SIM) improvement is also recommended by students. It consists of basic themes such as improvement in the use of instructions, 
more pictures, and examples, as well as more discussion of topics contained in students' SIMs. Doo, Bonk, and Heo (2020) suggested that when creating an online course, instructors and instructional designers should keep the social, teaching, and cognitive presences in mind. It is because self-regulation is an important topic in an online learning environment, and the instructional materials in an online course should be easy to access, comprehend, and engaging to students for successful learning. Furthermore, the assessment tool improvement highlighted the need of students for diverse assessment tools. Mostly, students are engaged with written activities like essays, so ensuring that there's the utilization of varied assessment methods in student's learning is essential to sustain the needs and interests of learners. Brockerhoff-Macdonald, Morrison, \& Manitowabi (2018) found out that providing preferred learning assessments to students will result in a more inclusive environment in online learning.

Certainly, existing gaps and barriers in asynchronous instruction can be addressed with teachers' pedagogical effort in supporting students, designing learning content, and developing self-regulated learners to effectively implement new modes of learning. This is anchored with the Transactional Distance Theory by Moore (1993), emphasizing that the perceived distance by students in distanced learning can be categorized into dialogue, structure, and autonomy. Closing the gap to these areas of concern is now an important concern for distance educators, administrators instructors, and other stakeholders to provide actions in mitigating the impact of these transactional distances on students learning (Best \& Conceição, 2017). Therefore, the recommendations given by students contribute to the continuous development of institutions, and teacher's in ensuring the quality of learning experience in asynchronous instruction, amid the challenges of the new normal education.

\subsection{Teacher's Training Proposal for GE 5 (Science, Technology and Society) Asynchronous Delivery Improvement}

Quantitative findings revealed that the implementation of GE 5 asynchronous instruction obtained high scores from the respondents with a descriptive meaning "excellent." The responses from the students allowed us to describe the learning experiences and identify the learning needs of students through qualitative analysis. From here, the training proposal is built. The activity aims to (1) inform teachers of the present struggle of students in the new normal education to reflect their crucial roles in learning; (2) train faculty instructors on the effective teaching strategies, modification of self-instructional materials, and learning assessment preferences among students in improving the asynchronous delivery of science courses like GE5 in the institution; and (3) attain a 100\% engagement rate from all identified faculty members and staff. 


\title{
5. Conclusion
}

Based on the aforementioned findings, we concluded that the level of implementation of asynchronous instruction in Science, Technology, and Society is excellent and that there is statistically no significant difference among their responses. Additionally, the students are having two-way (positive and negative) learning experiences. This means that even though the implementation is excellent in the overall evaluation, learners may still undergo negative learning experiences. Furthermore, the participants recommend asynchronous delivery improvement in terms of teachers, self-instructional manual (SIM), and assessment tools. The findings agree with Vygotsky's Social Constructivism Theory and Moore's Transactional Distance Theory.

\section{Recommendations}

The analysis and findings of the study helped us to formulate the following recommendations:

First, ensuring teachers' training for an effective asynchronous delivery improvement. Second, supporting the improvement for teaching delivery through actively participating and providing assistance in giving teachers the educational sessions and seminars to improve pedagogical, content, and technical skills of teachers in the new normal education. Third, ensuring that the content of the learning material being utilized is easy to use for students to maximize its function. Fourth, increasing the awareness and effective use of the varied assessment tools among teachers in sustaining the needs and interests of students in studying the course. Fifth, creating a safe learning environment for the students in asynchronous instruction is helpful towards the success of student learning in the course. Lastly, future researches should be conducted in revealing the significant factors which affect the learning experiences of students; and the other points that the current researchers have not yet explored.

\section{Conflict of Interest Statement}

The authors declare no conflicts of interests.

\begin{abstract}
About the Authors
Jeneva J. Diez; Ronna Joy C. Dequito; Emiernafe M. Ebro are undergraduate students taking a Bachelor of Secondary Education major in Science at the University of Mindanao Digos College, Philippines under the supervision of Mr. Tomas Jr A. Diquito. Their study has been presented at both local and international conferences. Their research interests include science education, teaching methodologies innovation, and learning experiences. Tomas Jr A. Diquito is a graduate of Master of Arts in Education major in Biology at the University of Southeastern Philippines. He is currently enrolled in PhD program at the
\end{abstract}


same University. He is a Licensed Teacher in his country, teaching both professional and specialized courses.

\section{References}

Alshammari, S. H. (2020). The Influence of Technical Support, Perceived Self-efficacy, and Instructional Design on Students' Use of Learning Management Systems. Turkish Online Journal of Distance Education, 21(3), 112-141. Retrieved from https://files.eric.ed.gov/fulltext/EJ1261606.pdf

Azzi-Huck, K., \& Shmis, T. (2020). Managing the impact of COVID-19 on education systems around the world: How countries are preparing, coping, and planning for recovery [Web log post]. Retrieved from https://blogs.worldbank.org/education/managing-impact-covid-19-educationsystems-around-world-how-countries-are-preparing

Berg, G. (2020). Context matters: Student experiences of interaction in open distance learning. Turkish Online Journal of Distance Education, 21(4), 223-236.

Best, B., \& Conceição, S. C. (2017). Transactional Distance Dialogic Interactions and Student Satisfaction in a Multi-Institutional Blended Learning Environment. European Journal of Open, Distance and E-learning, 20(1), 138-152.

Broadbent, J., \& Poon, W. L. (2015). Self-regulated learning strategies \& academic achievement in online higher education learning environments: A systematic review. The Internet and Higher Education, 27, 1-13.

Brockerhoff-Macdonald, B., Morrison, M., \& Manitowabi, S. (2018). Flexible weighting in online distance education courses.

Coman, C., Țîru, L. G., Meseșan-Schmitz, L., Stanciu, C., \& Bularca, M. C. (2020). Online teaching and learning in higher education during the coronavirus pandemic: students' perspective. Sustainability, 12(24), 10367.

Commission on Higher Education. (2020). 2020 CHED Memorandum Orders. CHED. https://ched.gov.ph/2020-ched-memorandum-orders/

Creswell J. W., Miller D. (2002). Determining validity in qualitative inquiry. Theory into Practice 39(3):124-130

Creswell, J. W. (2009). Research design: Qualitative, quantitative, and mixed methods approaches (3rd ed.). SAGE Publications, Inc.

Darling-Hammond, L., Flook, L., Cook-Harvey, C., Barron, B., \& Osher, D. (2019). Implications for educational practice of the science of learning and development. Applied Developmental Science, 24(2), 1-44. https://doi.org/10.1080/10888691.2018.1537791

Doo, M. Y., Bonk, C., \& Heo, H. (2020). A meta-analysis of scaffolding effects in online learning in higher education. International Review of Research in Open and Distributed Learning, 21(3), 60-80. 
Fisher, M. R., Jr., \& Bandy, J. (2019). Assessing Student Learning. Vanderbilt University Center for Teaching. Retrieved [todaysdate] from https://cft.vanderbilt.edu/assessing-student-learning/.

Ghaderizefreh, S., \& Hoover, M. L. (2018). Student Satisfaction with Online Learning in a Blended Course. International Journal for Digital Society, 9(3), 1393-1398. https://doi.org/10.20533/ijds.2040.2570.2018.0172

Hussin, W. N. T. W., Harun, J., \& Shukor, N. A. (2019). Online Interaction in Social Learning Environment towards Critical Thinking Skill: A Framework. Journal of Technology and Science Education, 9(1), 4-12.

Kelley, K. W., Fowlin, J. M., Tawfik, A. A., \& Anderson, M. C. (2019). The Role of Using Formative Assessments in Problem-based Learning: A Health Sciences Education Perspective. Interdisciplinary Journal of Problem-Based Learning, 13(2). https://doi.org/10.7771/1541-5015.1814

Li, N., Marsh, V., and Rienties, B., (2016). Modelling and managing learner satisfaction: Use of learner feedback to enhance blended and online learning experience. Decision Sciences Journal of Innovative Education, 14(2), 216-242.

Llemit, L. R. G. (2020, October 22). 3 out of 10 college students hesitant with learning in 'new normal.' Sunstar. Retrieved from https://www.sunstar.com.ph

Mahler, D., Großschedl, J., \& Harms, U. (2018). Does motivation matter?-The relationship between teachers' self-efficacy and enthusiasm and students' performance. PloS one, 13(11), e0207252.

Martin, F., Ritzhaupt, A., Kumar, S., \& Budhrani, K. (2019). Award-winning faculty online teaching practices: Course design, assessment and evaluation, and facilitation. The Internet and Higher Education, 42, 34-43. https://doi.org/10.1016/j.iheduc.2019.04.001

Meşe, E., \& Sevilen, Ç. (2021). Factors influencing EFL students' motivation in online learning: A qualitative case study. Journal of Educational Technology \& Online Learning, 4(1), 11-22. https://doi.org/10.31681/jetol

Moore, G. M. (1993). Theory of transactional distance. In D. Keegan (Ed.), Theoretical principles of distance education. New York, NY: Routledge. Retrieved on May 26, 2021,

from https://scholarworks.waldenu.edu/cgi/viewcontent.cgi?article=1187\&context=dis sertations

Southern Regional Education Board. (2006). Checklist for Evaluating Online Courses Educational Technology Cooperative. https://www.sreb.org/sites/main/files/fileattachments/06t06 checklist for evaluating-online-courses.pdf?1565877040

United Nations Educational, Scientific, and Cultural Organization. (2020). Education: From disruption to recovery. Retrieved from https://en.unesco.org/news/covid-19learning-disruption-recovery-snapshot-unescos-work-education-2020 
Villanueva, M. A. (2020, September 8). DepEd, CHED too distant to learners. Retrieved from https://www.philstar.com/opinion/2020/09/09/2041052/deped-ched-toodistant-learners

Vygotsky, L. (1978). Interaction between learning and development. Readings on the development of children, 23(3), 34-41.

Wu, Y. (2016). Factors impacting students' online learning experience in a learner-centred course. Journal of Computer Assisted Learning, 32(5), 416-429. https://doi.org/10.1111/jcal.12142. makes clear that the materials are being reused under permission of a Creative Commons License. Views, opinions and conclusions expressed in this research article are views, opinions and conclusions of the author(s). Open Access Publishing Group and European Journal of Education Studies shall not be responsible or answerable for any loss, damage or liability caused in relation to/arising out of conflicts of interest, copyright violations and inappropriate or inaccurate use of any kind content related or integrated into the research work. All the published works are meeting the Open Access Publishing requirements and can be freely accessed, shared, modified, distributed and used in educational, commercial and non-commercial purposes under a Creative Commons Attribution 4.0 International License (CC BY 4.0). 